\title{
Hirayama Disease
}

\author{
Murat KARADENIZ1 ${ }^{1}$, Özgür BOYRAZZ2, Kadir ÖZNAM³ ${ }^{3}$ Taner DANDINOĞLU4 \\ ${ }^{1}$ Department of Physical Medicine and Rehabilitation, Çorlu Military Hospital, Çorlu, Tekirdağ, Turkey \\ ${ }^{2}$ Department of Neurology, Çorlu Military Hospital, Çorlu, Tekirdağ, Turkey \\ ${ }^{3}$ Department of Orthopedics and Traumatology, Çorlu Military Hospital, Çorlu, Tekirdağ, Turkey \\ ${ }^{4}$ Department of Physical Medicine and Rehabilitation, Bursa Military Hospital, Bursa, Turkey
}

\begin{abstract}
Hirayama disease (HD) is a rare benign lower motor neuron disorder in the young with a male preponderance and usually affecting one upper extremity. It is characterized by the insidious onset and progressive weakness and wasting of a distal extremity. Generally, this disease is considered as a benign and nonprogressive motor neuron disease that stabilizes within five years of onset. We describe a 20 -year-old male patient who experienced left distal upper extremity amyotrophy with no sensorial abnormality.

Keywords: Hirayama disease, monomelic amyotrophy, motor neuron disease
\end{abstract}

\section{Introduction}

Hirayama disease (HD), also known as monomelic amyotrophy (MA), is a rare motor neuron disorder that affects one upper extremity (1). It was identified for the first time in 1959 by Hirayama et al., and they pointed out that these clinical findings do not fit any of the previously known diseases that cause degenerative and progressive muscular atrophy (2,3). Later, these clinical findings were identified in detail in 38 patients by Hirayama et al. This clinical picture was called as juvenile spinal muscular atrophy, juvenile asymmetric segmental spinal muscular atrophy (4), juvenile muscular atrophy of unilateral upper extremity (5), or Madras pattern of motor neuron disease $(2,6,7)$. It has been mostly reported in Japan, India, Sri Lanka, Korea, Hong Kong, Taiwan, and Malaysia $(2,4)$. The number of cases reported from Western countries is very low (8).

Men are affected by this disease five times more often than women (2). It is generally seen among young people who are in a period of rapid growth. Its incidence peaks at the age of 15-25 years $(7,9)$. Clinical findings appear in the second or third decade and progress slowly (6). In this disease, unilateral or asymmetric bilateral muscle weakness and atrophy, which progress slowly, occur in the hands and forearm. The disease is limited to upper extremity motor neuron involvement; lower extremity, sensory, or bulbar involvement is not observed $(7,10)$. In some cases, muscle weakness becomes evident in cold weather. Patients express that while weakness in fingers increases in cold weather, it gets normal in warm weather. Therefore, patients discover their disease for the first time during winter months. It is rarely seen with hyperhidrosis and abnormal sympathetic skin responses (8). In $20 \%$ of the cases, weakness of the upper arm can be seen. It displays asymmetrical and varying degrees of involvement in the thenar, hypothenar, and interosseous muscles of the hand. While atrophy develops in the distal forearm and ulnar part, due to atrophy caused by lower cervical segment damage, the brachioradialis muscle (oblique amyotrophy) innervated by $\mathrm{C} 6$ is usually recovered. The cause of this disease 


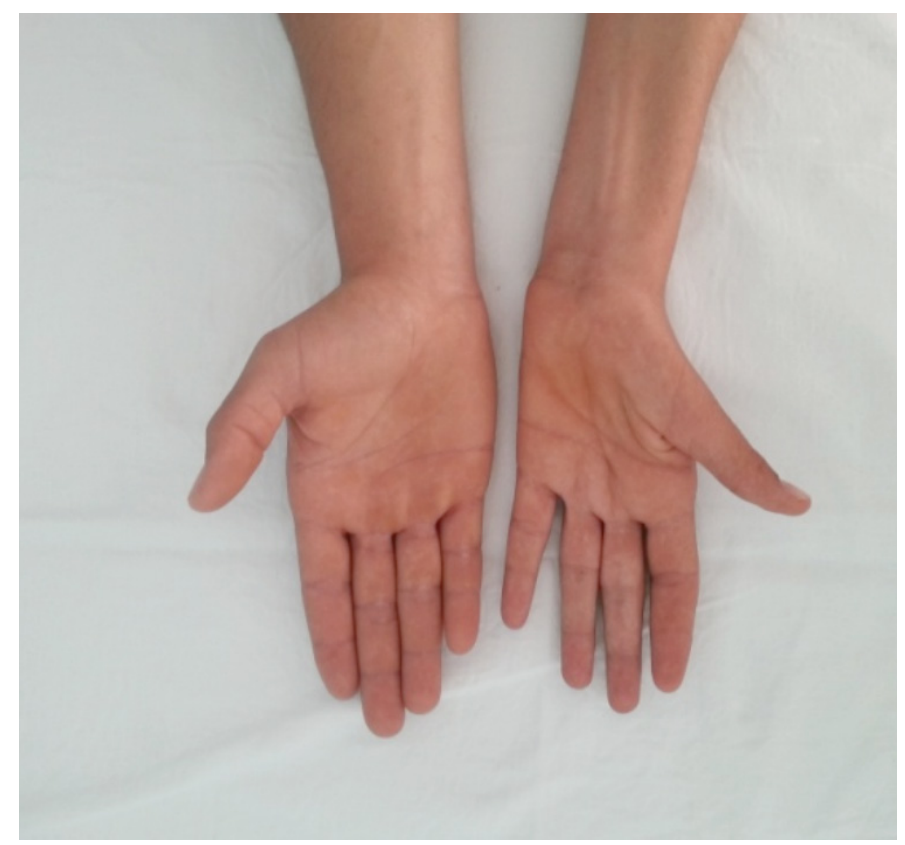

Figure 1. Atrophy of the thenar and hypothenar areas in the left hand

is unknown. However, theories such as chronic spinal cord compression or atopy have been suggested (8). In particular, crushed and flattened spine due to excessive forward displacement of the dural sac during cervical spine flexion and ischemic changes resulting from this situation are thought to be responsible for spinal anterior horn damage, which causes a clinical picture (11). In addition, on pre- and post-contrast neutral and flexion positioned cervical magnetic resonance imaging, localized lower cervical cord atrophy, straightening of the asymmetric cord, abnormal cervical curvature, loss of connection between the basal lamina and posterior dural sac, forward displacement of the posterior wall of the dural canal, and expansion of epidural component symptoms have been observed (12). Familial incidence is very low, and very few cases of autosomal recessively inherited disorders have been reported $(1,2,7,8)$. In this article, we describe the case of a 20-year-old male patient who was admitted to our hospital with complaints of weakness and wasting of the left hand.

\section{Case Report}

A 20-year-old male patient, who was admitted to our clinic with complaints of weakness, muscle wasting, and deformation in the left hand, noticed weakness of his hand when he was approximately 16 years old. In his history, it was revealed that he experienced occasional numbness and chills in his left arm and that he was unable to carry any load using that hand for a long time. Except for the fact that he had measles when he was 2 months old, chickenpox when he was 5 months old, and febrile illness when he was in elementary school, nothing significant was found in his medical history. Nothing significant was found in his family history. Physical examination findings were within normal limits. A neurological examination showed that his left and left forearms were in atrophic formation (Figures 1,2) and that apparent atrophy was observed in the distal brachioradia-

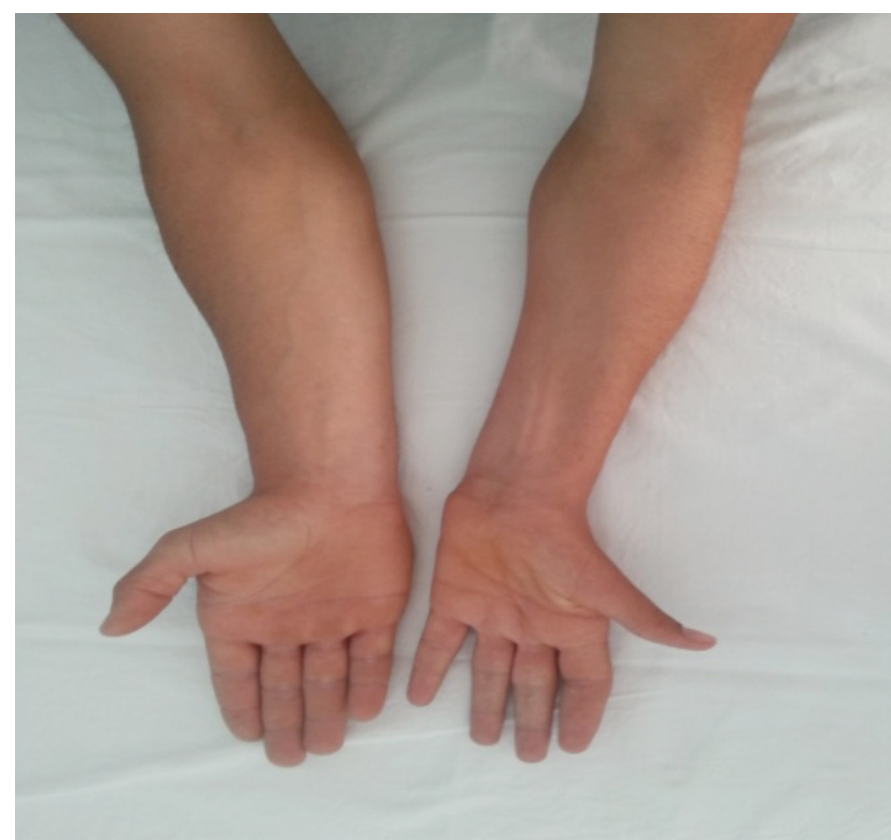

Figure 2. Forearm and hand atrophy in the distal part of the left brachioradialis muscle

lis muscle of his left forearm and in his left hand thenar, hypothenar, and interosseous muscles. The strength of his left hand hypothenar abductor digiti minimi and opponens digiti minimi muscles was 3/5, and that of his left hand thenar abductor pollicis brevis, opponens pollicis, flexor pollicis, adductor pollicis and left hand palmar interosseous and lumbrical muscles was $3 / 5$. The strength of his left forearm flexor pollicis longus, flexor digitorum superficialis and profundus, abductor pollicis longus, extensor indicis, extensor pollicis brevis and longus, and extensor carpi ulnaris and radial muscles was evaluated to be $3 / 5$. The distal interphalangeal joint muscle strength of the fingers was $3 / 5$, and in the proximal end, it was $3 / 5$. Measurements on the forearm proximal from $5 \mathrm{~cm}$ elbow distal were $28 \mathrm{~cm}$ in the right arm and $24.5 \mathrm{~cm}$ in the left arm, and atrophy of 3.5 $\mathrm{cm}$ was detected in the left arm. Measurements on the forearm distal from $5 \mathrm{~cm}$ elbow proximal were $21.5 \mathrm{~cm}$ in the right arm and $17.5 \mathrm{~cm}$ in the left arm, and atrophy of $4 \mathrm{~cm}$ was detected in the left arm. No atrophy was detected in the upper arm measurements. All values in hemogram and biochemical tests were found to be within normal limits. Thyroid function test results and creatine kinase levels were also within normal limits. Except for a non-compressive diffuse bulging appearance that slightly narrowed the anterior subarachnoid space in the C5-C6 intervertebral disc on cervical spine magnetic resonance imaging (MRI), no pathological findings were observed (Figures 3,4). Brachial plexus MRI evaluation was normal. Electromyography (EMG) examination was performed using a Medelec Synergy EMG device (Medelec Limited, Old Woking, Surrey, UK) in our hospital, and the right median, ulnar, and peroneal nerve conduction evaluation on EMG was within the normal limits. The left median and ulnar sensory nerve conduction was normal. It was observed that on the left median and ulnar nerve, tempo- 


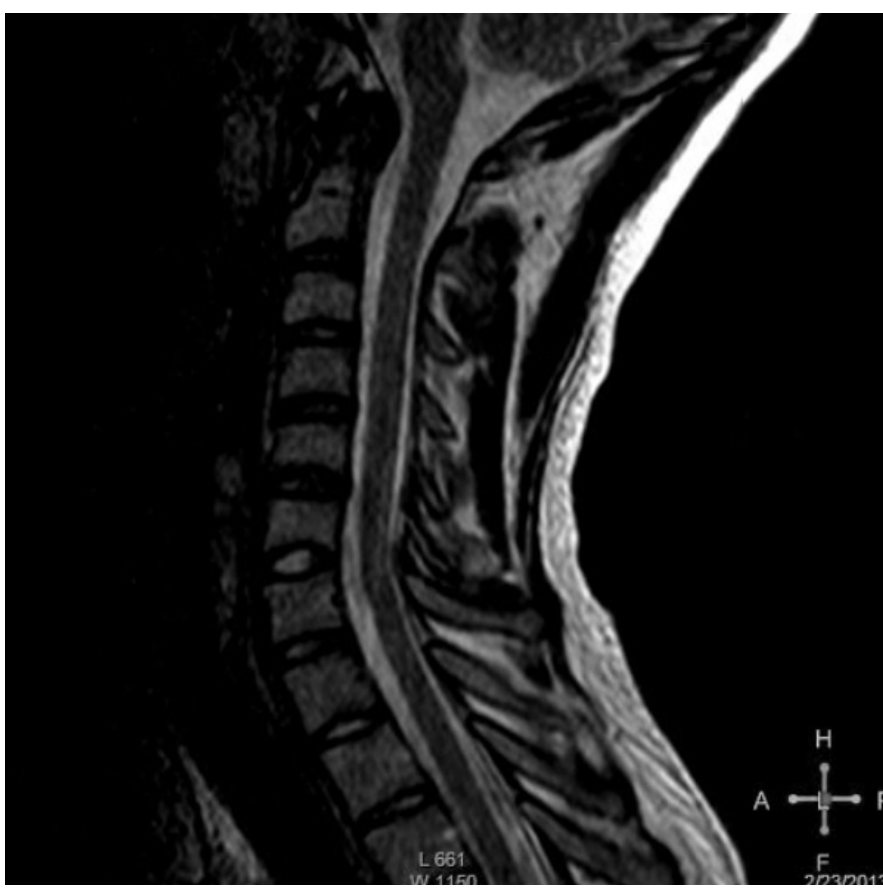

Figure 3. Cervical MRI longitudinal section MRI: magnetic resonance imaging

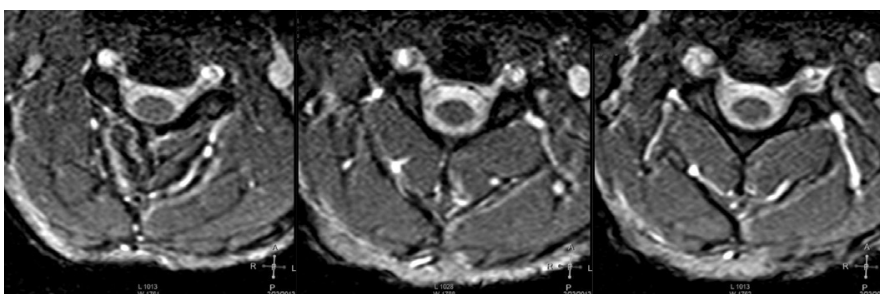

Figure 4. Cervical MRI axial section

MRI: magnetic resonance imaging

ral disperse responses and compound muscle action potential (CMAP) amplitudes were low (CMAP $=0.3 \mathrm{mV})$, and $\mathrm{F}$ responses were absent. In a needle EMG examination, in the left median nerve innervated muscles, spontaneous fibrillation and positive sharp waves, polyphase, dilution in the maximal muscle and expansion in the left ulnar nerve innervated muscle motor units, large amplitude motor units, and partial denervation symptoms such as dilution in the maximal muscle were observed. It was detected that symptoms consistent with anterior horn cell involvement were limited in the left $\mathrm{C} 7, \mathrm{C} 8$, and $\mathrm{T} 1$ myotomes. The patient was diagnosed with MA based on these findings. When the patient was functionally assessed, except for skills requiring advanced skills, his left hand was independent in daily life activities. A difficulty was observed in his left hand grip. The patient was informed that his clinical information would be used for scientific purposes, and his verbal consent was obtained.

\section{Discussion}

Monomelic amyotrophy is usually sporadic. With an insidious onset, self-limiting weakness and atrophy develop in the hand and forearm (9). In our case, a typical onset for MA is described. Apart from single-sided atrophy of the forearm and hand muscles and weakness, cold paresis is described. In literature, MA is reported to be more common among young males, especially between the ages of 15 and 27 years (9). Men are affected by this disease five times more often than women. According to age and gender, our 20-year-old male patient was placed in the group compatible with that in literature. Nalini et al. (8) reported that in a series of 190 patients, only a single case of familial MA was found. Hirayama (3) reported that this disease was found in a father and his son in one family and two brothers in two families. Because a similar disease history had not been detected in our patient's family, his case was recognized to be a sporadic case.

The brachioradialis muscle remains intact while atrophy develops in the ulnar and distal parts of the forearm. The border of the atrophy goes to the palm and dorsal side of the forearm and to the radial region of the elbow obliquely. The growing weakness in the fingers and wrist affects both flexor and extensor muscles. Usually, retention is more pronounced in the extensors of the fingers and wrist. Atrophy is not seen in the face, neck, chest, and legs. Muscle weakness and atrophy are unilaterally observed in more than half of the patients, and the bilateral form is observed in one-third of the patients. During the rest period, no involuntary movements are observed in the hands, but when the fingers are slightly moved, irregular non-synchronized tremors occur (2). We did not observe any tremors or involuntary movements in our patient. The patient presented to us 4 years after he had noticed weakness in his hand; however, because it was the late stage of the disease, we may not have seen these involuntary movements. In more than four-fifth of the patients, cold paresis has been reported $(3,4,8)$. There were similar complaints in our patient also. Furthermore, he was complaining of paresthesia with coldness in the hands and arms. Although abnormalities in hyperhidrosis and sympathetic skin responses were reported in some patients, our patient did not have much sweating and his sympathetic skin responses were normal.

Nerve conduction study results in most MA patients are normal (4). However, atypical cases showing decrease in CMAP amplitudes and slowing down in conduction velocity have also been reported. In the study conducted by Hamano et al. (13), it was noted that there is a decrease in the conduction velocity and CMAP amplitude in the affected limb. In the conduction velocity studies that we performed in this case, we found that the left median and ulnar temporal disperse responses and CMAP amplitude were diminished and that there were no $F$ responses. This change in conduction velocity and amplitudes can be interpreted as a consequence of denervation in affected muscles (13). EMG states typical neurogenic symptoms conforming to the anterior horn cell involvement in atrophic muscles. In the other arm, although there is no atrophy, with approximately $10 \%$ possibility, symptoms conforming to anterior horn cell involvement are identified $(2,7)$. In our patient, symptoms of atrophy were present only in the left forearm and hand, showing that there was anterior horn cell involvement. In these muscles that 
conform to C7, C8, and T1 myotomes, denervation symptoms such as expansion in motor unit duration, polyphase, fibrillation, positive sharp waves, and dilution in the maximal muscle were found. There are authors indicating that in some patients, intrinsic cord pathologies are detected on cervical MRI $(11,12,14,15)$. In some patients, the central cavity MRI of the cervical region of the medulla spinalis reveals the congestion of epidural venous plexus and neck movements (2). In our patient, the cervical MRI that had been performed in another hospital showed that in the C5-C6 intervertebral disc, no pathological findings were found, except for the non-compressive diffuse bulging appearance that slightly narrowed the anterior subarachnoid space. The brachial plexus MRI evaluation was normal. Cross-amyotrophy in lower cervical spinal involvement may occur in the early stages of syringomyelia. In the early stages of amyotrophic lateral sclerosis (ALS), similar distal amyotrophy in the forearm and hand might be seen, but typical fasciculations spreading to the upper arm are seen in the period for rest in ALS (2). In our patient, no such fasciculations were detected. Treatment is determined according to the pathology. Therefore, it is important to investigate the etiology in MA patients. If the spinal dural channel in the lower cervical region is detected to be shifted forward, the aim of the treatment is to prevent the dural channel from shifting forward and to restore it. Furthermore, a neck brace must be used to prevent excessive flexion of the head. In our patient, as no pathology was etiologically detected and our patient was in the late stage, no treatment was started. To maintain the present functions of the patient, a home exercise program that included joint range of motion exercises was recommended.

\section{Conclusion}

Hirayama disease should be considered in the differential diagnosis of young men with forearm and hand muscle atrophy. As early diagnosis is crucially important for the treatment of suspected patients, dynamic flexion MRI should be performed. With the help of early treatment modalities, the prognosis of the disease progresses more benign.

Informed Consent: Verbal informed consent was obtained from patient who participated in this case.

Peer-review: Externally peer-reviewed.

Author Contributions: Concept - Ö.B.; Design - Ö.B.; Supervision - M.K., K.Ö.; Resource - Ö.B.; Materials - M.K.; Data Collection and/or Processing - Ö.B.; Analysis and/or Interpretation - M.K.; Literature Review - Ö.B., K.Ö., T.D.; Writer - Ö.B., M.K.; Critical Review - K.Ö., T.D.; Other - M.K.
Conflict of Interest: No conflict of interest was declared by the authors.

Financial Disclosure: The authors declared that this study has received no financial support.

\section{References}

1. Fetoni V, Briem E, Carrara F, Mora M, Zeviani M. Monomelic amyotrophy associated with the 7472insC mutation in the mtDNA tRNA gene. Neuromuscul Disord 2004;14:723-6. [CrossRef]

2. Tuncbay T, Tuncbay E. Nöromuskuler Hastalıklar. Izmir: Ege Üniversitesi Basım Evi, 2000:136-40.

3. Hirayama K, Toyokura Y, Tsubaki T. Juvenile musculer atrophy unilateral upper extremity: a new clinical entity. Psychiatr Neurol Jpn 1959;61:2190-7.

4. Gourie-Devi M, Nalini A. Long term follow-up of 44 patients with brachial monomelic amyotrophy. Acta Neurol Scand 2003;107:215-20. [CrossRef]

5. Kohno M, Takahashi H, Yagishita A, Tanabe H. "Disproportion theory" of the cervical spine and spinal cord in patients with juvenil cervical flexion myelopathy: A study comparing cervical magnetic resonance images with those of normal controls. Surg Neurol 1998;50:421-30. [CrossRef]

6. Massa R, Scalise A, Iani C, Palmieri MG, Bernardi G. Delayed focal involvement of upper motor neurons in the Madras pattern of motor neuron disease. Electroencephalogr Clin Neurophysiol 1998;109:523-6. [CrossRef]

7. Rowin J, Meriggioli MN, Cochran EJ. Monomelic amyotrophy with late progression. Neuromuscul Disord 2001;11:305-8. [CrossRef]

8. Nalini A, Lokesh L, Ratnavalli E. Familial monomelic amyotrophy: a case report from India. J Neurol Sci 2004;220:95-8. [CrossRef]

9. Kiernan MC, Lethlean AK, Blum PW. Monomelic amyotrophy: non progressive atrophy of the upper limb. J Clin Neurosci 1999;6:353-5. [CrossRef]

10. O'Sullivan, McLeod JG. Distal chronic spinal muscular atrophy involving the hands. J Neurol Neurosurg Psychiatry 1978;41:653-8. [CrossRef]

11. Chen Cl, Chen CM, Wu CL, Ro LS, Chen ST, Lee TH. Hirayama disease: MR Diagnosis. AJNR Am J Neuroradiol 1998;19:365-8.

12. Sonwalkar HA, Shah RS, Khan FK, Gupta AK, Bodhey NK, Vottath $S$, et al. Imaging features in Hirayama disease. Neurol India 2008;56:22-6. [CrossRef]

13. Hamano T, Mutoh T, Hirayama M, Ito K, Kimura M, Aita T, et al. MRI findings of bening monomelic amyotrophy of lower limb. J Neurol Sci 1999;165:184-7. [CrossRef]

14. Schröder R, Keller E, Flacke S, Schmidt S, Pohl C, Klockgether T, et al. MRI findings in Hirayama's Disease: flexion induced cervical myelopathy or intrinsic motor neuron disease? J Neurol 1999;246:1069-74. [CrossRef]

15. Pradhan S, Gupta RK. Magnetic resonance imaging in juvenile asymmetric segmental spinal muscular atrophy. I Neurol Sci 1997;146:133-8. [CrossRef] 